\title{
PENENTUAN FAKTOR BERPENGARUH PADA EKSTRAKSI RIMPANG JAHE MENGGUNAKAN EXTRAKTOR BERPENGADUK
}

\author{
Giovani Anggista, Ilyas Teguh Pangestu, Dwi Handayani, M. Endy Yulianto, Septi Kusuma \\ Program Studi Diploma III Teknik Kimia, Departemen Teknologi Industri Sekolah Vokasi, \\ Universitas Diponegoro \\ Jl. Prof. Soedarto, Tembalang, Kota Semarang, Jawa Tengah 50275 \\ ${ }^{*}$ Email : ilyaspangestu26@gmail.com
}

\begin{abstract}
Giovani Anggista, Ilyas Teguh Pangestu, Dwi Handayani, M. Endy Yulianto, Septi Kusuma, in this paper explain that the main part of ginger used is rhizome. Processed ginger products that can be developed are ginger oleoresin which contains components of gingerol, shogaol, zingerone, resin and essential oils. Ginger oleoresin content ranges from $3.2-9.5 \%$, while the content of gingerol in oleoresin is between 14-25\% and shogaol between oleoresin. 2.8-7.0\%. Considering the benefits of high-antioxidant ginger which functions as an antiinflammatory and prevents tumor growth, it is necessary to extract the ginger rhizome. The purpose of this study was to determine the factors that most influence the extraction of gingerol from the ginger rhizome using a stirred extractor and relatively good conditions. Experiments were carried out with various solvents, $p H$ and temperature. Solvents 4 liters and 8 liters, $p H 4$ and 6 and temperatures $60^{\circ} \mathrm{C}$ and $100^{\circ} \mathrm{C}$. The Gingerol content is measured by a VIS spectrophotometer. The most influential factor in extraction of ginger was determined by experimental design 23. The analysis of the results showed that for extracting 500 grams of powdered ginger using water as a solvent, the most influential factor was $\mathrm{pH}$, in this case, at $\mathrm{pH} 6$ containing $4 \%$ ginger.
\end{abstract}

Keywords: Extraction; Ginger; Gingerol; Spectrophotometer; Temperature;

\section{PENDAHULUAN}

Tanaman jahe termasuk keluarga Zingiberaceae, yang merupakan herba kronis, akar berserat, dan termasuk dalam monokotil. Morfologi jahe pada umumnya terdiri atas struktur rimpang, batang, daun, bunga, dan buah[1]. Bagian utama dari jahe yang digunakan adalah rimpang[2]. Produk olahan jahe yang dapat dikembangkan adalah jahe oleoresin yang mengandung komponen gingerol, shogaol, zingerone, resin dan minyak atsiri. Kandungan oleoresin jahe berkisar antara 3,2-9,5\%, sedangkan kandungan gingerol dalam oleoresin antara $14-25 \%$ dan shogaol di antara oleoresin 2,8$7,0 \%$ [3]. Senyawa aktif yang terkandung dalam jahe seperti gingerol, shogaol, dan paradol diselidiki memiliki sifat anti-inflamasi, antioksidan, antibakteri, dan anti-platelet[4]. Gingerol juga memiliki efek analgesik, sedatif dan antibakteri secara in vitro dan in vivo[5]. Jahe juga mengandung sejumlah minyak atsiri di akarnya. Selain itu, mengandung bahan kimia lain seperti seskuiterpenoid dan monoterpenoid dalam jumlah yang lebih kecil[6]. Kandungan gingerol yang rendah dalam ekstrak jahe, yang diperoleh dari proses ekstraksi konvensional biasanya dikaitkan dengan degradasi termal karena gingerol adalah senyawa termolabil[7]. Proses ekstraksi konvensional membutuhkan waktu antara 10-18 jam untuk menghasilkan minyak jahe, suatu proses yang meningkatkan risiko degradasi termal gingerol[8].

Untuk mengekstraksi kandungan Gingerol yang terkandung dalam jahe akan dilakukan ekstraksi menggunakan pelarut. Ekstraksi adalah proses pemisahan komponen dari bahan padat atau cair dengan bantuan pelarut. Pelarut yang digunakan harus mampu mengekstraksi zat yang diinginkan tanpa melarutkan bahan lain[9]. Gingerol yang diekstraksi dapat mengalami dehidrasi, selama penyimpanan dan pemrosesan, untuk membentuk shogaol yang cocok. Studi yang dilakukan sejauh ini terutama berfokus pada aktivitas gingerol bilier untuk anti-inflamasi[10].

Ekstraksi gingerol dilakukan dengan proses ekstraksi kohobasi. Ekstraksi kohobasi adalah proses pemurnian yang diulangi lagi, yang berarti bahwa air keluaran yang tersisa dimasukkan ke dalam boiler lain untuk diolah kembali menjadi uap, kemudian uap dialirkan ke tabung destilasi. Dalam tabung destilasi, kontak dengan bahan baku menghasilkan air kukus dan ekstrak gingerol, kemudian dipisahkan oleh pemisah untuk menghasilkan ekstrak gingerol. Mekanisme ekstraksi gingerol adalah sebagai berikut: pelarut aquadest berdifusi menjadi padatan (bubuk jahe), kemudian larut (ekstrak gingerol) larut dalam pelarut. Larutan yang bercampur dengan pelarut kemudian berdifusi keluar dari padatan, pelarut yang dicampur dengan zat terlarut berdifusi ke permukaan luar partikel. Perpindahan pelarut biasanya terjadi lebih awal ketika partikel-partikel untuk pertama kalinya dikontakkan dengan pelarut[11].

Faktor-faktor yang mempengaruhi ekstraksi adalah suhu operasi, kecepatan pengadukan, ukuran, bentuk, dan kondisi partikel padat, jenis, dan jumlah pelarut. Peristiwa fisik yang terjadi dalam proses ekstraksi adalah perpindahan massa. Transfer massa ini terjadi karena perbedaan konsentrasi dari konsentrasi tinggi ke konsentrasi yang lebih 
rendah[12]. Semakin besar perbedaan konsentrasi semakin cepat perpindahan massa terjadi dan pencapaian keseimbangan[13].

Evaluasi pengaruh parameter proses (suhu, rasio enzim-substrat dan waktu ekstraksi) pada ekstraksi enzimatik menggunakan isolat enzim amobil rumen terhadap produksi minyak jahe dari pulp jahe telah dilakukan dan disimpulkan bahwa waktu ekstraksi adalah faktor yang paling berpengaruh. Pada $\mathrm{pH} 4$ dan $\mathrm{pH}$ 5, kondisi optimal dicapai ketika enzim rumen digunakan pada rasio 1 : 5 pada $60^{\circ} \mathrm{C}$ dan dengan waktu ekstraksi 5 jam. Minyak jahe yang diperoleh memiliki kandungan zingiberene masing-masing $21,56 \%$ dan 26,28\% untuk pH 4 dan 5. Ekstraksi untuk periode yang lebih lama menghasilkan pengurangan kandungan zingiberene[14].

Mengingat manfaat dari jahe yang mengandung antioksidan tinggi yang berfungsi sebagai antiinflamasi dan mencegah pertumbuhan tumor, maka perlu untuk mengekstrak rimpang jahe untuk menentukan jumlah gingerol yang diekstraksi. Tujuan penelitian adalah untuk menentukan kondisi terbaik pada ukuran bahan tertentu, jenis pelarut, waktu dan suhu yang tepat dalam proses ekstraksi yang akan menghasilkan jahe oleoresin dan manfaatnya diharapkan dapat memberikan informasi tambahan tentang kondisi ekstraksi terbaik dalam memproduksi hasil oleoresin pada jahe. Hasil penelitian ini diharapkan dapat meningkatkan nilai ekonomi tanaman, terutama untuk meningkatkan pendapatan petani. Hipotesis ini diduga memiliki jenis pelarut yang tepat serta waktu dan suhu dalam proses ekstraksi yang optimal dalam menghasilkan hasil jahe oleoresin, dan diduga ada interaksi antara jenis pelarut, suhu dan waktu ekstraksi yang diperlukan. untuk hasil dan kualitas jahe oleoresin.

\section{METODOLOGI} adalah :

Bahan yang digunakan untuk penelitian ini

- 500 gram bubuk jahe dari UKM jahe di Ungaran.

- $\mathrm{CH} 3 \mathrm{COOH}$ dan $\mathrm{NaOH}$ digunakan untuk mengontrol $\mathrm{pH}$ agar sesuai dengan variabel yang diinginkan yang diperoleh dari Indrasari

- Pelarut (air)

Alat utama yang digunakan dalam penelitian ini adalah ekstraktor yang diaduk yang ditunjukkan pada Gambar 1.

Variabel operasi selama penelitian terdiri dari variabel kontrol, variabel independen, dan variabel dependen.

Variabel kontrol terdiri dari: (i) berat bahan: 500 gram / batch; (ii) kecepatan pengadukan: 20 rpm; (iii) waktu ekstraksi: 30 menit.

Variabel independen terdiri dari: (i) jumlah pelarut: 4 liter (-) dan 8 liter (+); (ii) $\mathrm{pH}: 4$ (-) dan 8 (+); (iii) suhu: $60^{\circ} \mathrm{C} \mathrm{(-)} \mathrm{dan} 100^{\circ} \mathrm{C} \mathrm{(+).}$

Variabel dependen dalam penelitian ini adalah jumlah gingerol yang diekstraksi.
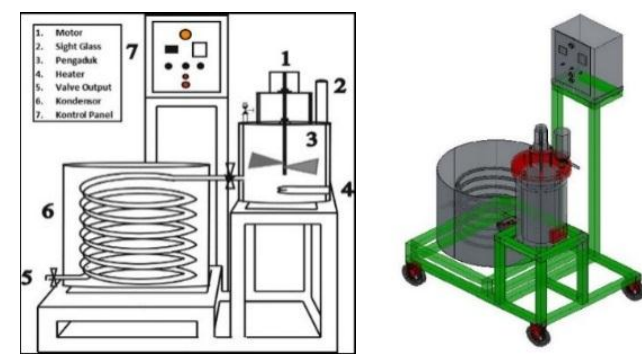

Gambar 1. Ekstraktor Berpengaduk

Ekstraksi dilakukan menggunakan ekstraktor berpengaduk (Gambar 1) yang dilengkapi dengan kondensor. Bahannya adalah 500 gram bubuk jahe yang dilarutkan dalam air sesuai variabel. Kemudian ukur $\mathrm{pH}$ campuran agar sesuai dengan variabel. Jika $\mathrm{pH}$ kurang asam maka $\mathrm{CH} 3 \mathrm{COOH}$ ditambahkan dan jika $\mathrm{pH}$ kurang basa maka $\mathrm{NaOH}$ ditambahkan. Proses ekstraksi dilakukan selama 30 menit dengan kecepatan pengadukan extractor hingga $20 \mathrm{rpm}$ dan suhu sesuai dengan variabel pada panel kontrol. Masukkan sampel melalui inlet, jika telah mencapai titik suhu yang diatur, hitung waktu ekstraksi. Setelah proses ekstraksi adalah 30 menit, ekstrak hasilnya melalui output katup.

Metode analitik yang digunakan adalah dengan spektrofotometri, untuk menghitung hasil absorbansi dari spektrofotometer berdasarkan hukum Lambert-Beer, itu akan dikenal sebagai tingkat gingerol yang diproduksi.

Penelitian ini dilakukan dengan eksperimen dan pengolahan data dengan desain eksperimen $2^{3}$ untuk memperoleh data yang berguna dalam menentukan parameter yang paling berpengaruh dalam proses produksi. Desain eksperimental adalah salah satu metode yang sering digunakan dibandingkan dengan pendekatan konvensional lainnya, karena memiliki beberapa keunggulan, yaitu: (i) membutuhkan desain eksperimen lebih sedikit $2^{3}$ untuk mengetahui pengaruh dari semua variabel; (ii) kondisi optimal diperoleh lebih tepat karena mencakup faktor interaksi; dan (iii) kesimpulan lebih pasti karena didukung oleh metode perhitungan statistik sederhana. Desain eksperimental ditunjukkan pada Tabel 1.

\section{HASIL DAN PEMBAHASAN}

Peralatan penelitian dirancang dan dianalisis menggunakan sistem desain eksperimental, yang berarti serangkaian eksperimen dirancang untuk memperoleh data konkret untuk membuktikan hipotesis. Dalam desain eksperimental, masingmasing variabel yang diuji ditentukan pada beberapa nilai; dalam penelitian ini tiga nilai untuk variabel independen. Variabel independen ini kemudian 
digabungkan. Kombinasi variabel independen memungkinkan data diperoleh yang akan membantu mencapai kesimpulan dengan menggunakan metode statistik.

Tabel 1. Desain eksperimental

\begin{tabular}{ccc}
\hline $\begin{array}{c}\text { Jumlah } \\
\text { Pelarut } \\
\text { (liter) }\end{array}$ & pH & $\begin{array}{c}\text { Suhu } \\
\left({ }^{\circ} \mathbf{C}\right)\end{array}$ \\
\hline 4 & 4 & 60 \\
8 & 4 & 60 \\
4 & 6 & 60 \\
8 & 6 & 60 \\
4 & 4 & 100 \\
8 & 4 & 100 \\
4 & 6 & 100 \\
8 & 6 & 100 \\
\hline
\end{tabular}

Tabel 2. Hasil eksperimental

\begin{tabular}{ccccc}
\hline No & $\begin{array}{c}\text { Pelarut } \\
\text { (liter) }\end{array}$ & $\mathbf{p H}$ & $\begin{array}{c}\text { Suhu } \\
\left({ }^{\mathbf{0}} \mathbf{C}\right)\end{array}$ & $\begin{array}{c}\text { Kandungan } \\
\text { Gingerol } \\
(\boldsymbol{\%})\end{array}$ \\
\hline 1 & 4 & 4 & 60 & 2,176 \\
2 & 8 & 4 & 60 & 2,880 \\
3 & 4 & 6 & 60 & 2,164 \\
4 & 8 & 6 & 60 & 0,500 \\
5 & 4 & 4 & 100 & 0,694 \\
6 & 8 & 4 & 100 & 2,200 \\
7 & 4 & 6 & 100 & 1,819 \\
8 & 8 & 6 & 100 & 4,000 \\
\hline
\end{tabular}

Table 3. Experimental Research

\begin{tabular}{ccccccccc}
\hline No & & Faktor & & $\begin{array}{l}\text { Kandungan } \\
\text { Gingerol (\%) }\end{array}$ & Pembagi & Pengaruh & & \\
& A & B & C & & & & Hasil & Probabilitas (\%) \\
\hline 1 & -1 & -1 & -1 & 2,176 & 8 & Average & & \\
2 & 1 & -1 & -1 & 2,880 & 4 & A & 1,33 & 7,14 \\
3 & -1 & 1 & -1 & 2,164 & 4 & B & 1,16 & 21,43 \\
4 & 1 & 1 & -1 & 0,500 & 4 & AB & 0,76 & 35,71 \\
5 & -1 & -1 & 1 & 0,694 & 4 & C & 0,68 & 50,00 \\
6 & 1 & -1 & 1 & 2,200 & 4 & AC & 0,25 & 64,29 \\
7 & -1 & 1 & 1 & 1,819 & 4 & BC & 0,42 & 78,57 \\
8 & 1 & 1 & 1 & 4,000 & 4 & ABC & 0,13 & 92,86 \\
\hline
\end{tabular}

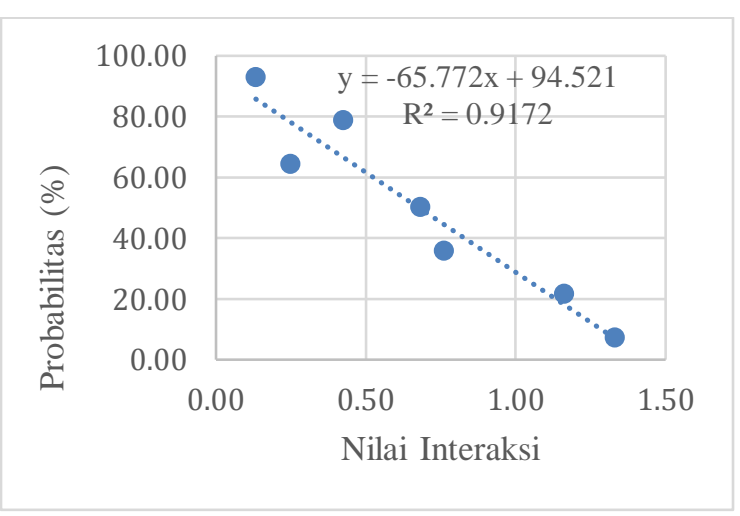

Gambar 2. Nilai efek interaksi dalam hasil eksperimental

Gambar 2 menunjukkan bahwa nilai efek interaksi sesuai dengan persamaan $\mathrm{Y}=14.927 \mathrm{X}+$ 4.0632 dengan $\mathrm{R}^{2}=0,9172$ dan faktor yang paling berpengaruh adalah $\mathrm{pH}$.
Dari hasil analisis regresi dilakukan pada nilainilai efek interaksi dan persentase probabilitas menggunakan program Matlab, sehingga pengaruh variabel pada proses ekstraksi Gingerol dapat ditentukan. Tabel 2 menunjukkan hasil konten Gingerol. Nilai efek yang diperkirakan dan nilai probabilitas dari percobaan yang dilakukan ditunjukkan pada Tabel 3 dan Gambar 3.

Gambar 2 menunjukkan efek interaksi ekstraksi Gingerol. Penelitian menunjukkan bahwa efek interaksi sesuai dengan persamaan $\mathrm{Y}=14.927 \mathrm{X}$ +4.0632 , dengan $\mathrm{R}^{2}=0,9172$. $\mathrm{PH}$ juga ditemukan sebagai faktor yang paling berpengaruh. Dalam ekstraksi dengan pelarut 8 liter pada $\mathrm{pH} 6$ dan $100^{\circ} \mathrm{C}$, kandungan Gingerol 4\%. Kedua set percobaan menunjukkan bahwa faktor yang mempengaruhi ekstraksi adalah pH. Ekstraksi pada $\mathrm{pH} 4$ menghasilkan kandungan Gingerol yang lebih rendah 0,694\% (Tabel 2).

Aroma jahe tergantung pada komponen minyak atsiri yang dapat mecapai 1-3\%. Lebih dari 50 komponen minyak jahe telah berhasil dikarakterisasi 
dan umumnya dalam bentuk senyawa monoterpenoid seperti fenantrena, camphene dan borneol; dan senyawa seskuiterpen seperti zingiberene dan zingiberol[15].

Sementara itu, karakteristik rasa pedas dari jahe juga ditemukan dalam jahe oleoresin disebabkan oleh adanya senyawa gingerol. Gingerol adalah serangkaian senyawa fenol yang homolog. Gingerol (Gambar 3) adalah senyawa fenil alkil keton yang merupakan turunan dari vanilin. Gingerol atau 1- (3'methoxy-4'-hydroxyphenyl) - 5 hydroxyalkanes-3ones memiliki berbagai rantai samping. Rantai samping senyawa gingerol yang telah diidentifikasi adalah (3) -, (4) -, (5) -, (6) -, (8) -, (10) -, dan (12) gingerol berturut-turut atom karbon $7,8,9,10,12,14$, dan 16.

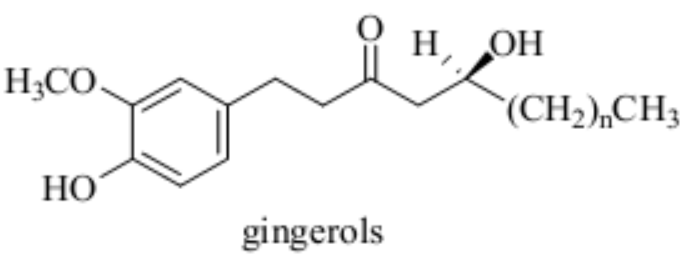

Gambar 3. Gingerol

Beberapa proses telah dilakukan untuk mendapatkan senyawa gingerol aktif tinggi seperti proses ekstraksi dengan pemanasan awal (pendidihan dan pemanggangan)[16]. Menunjukkan bahwa ekstrak hidrotermal yang mengandung senyawa gingerol mencapai $5 \%$ pada suhu $130^{\circ} \mathrm{C}$, tekanan 2 bar selama 20 menit[17]. Kandungan senyawa gingerol dalam ekstrak hidrotermal jahe jauh lebih besar jika dibandingkan dengan kadar gingerol yang dihasilkan dari aplikasi proses perebusan dan proses pemanggangan. Memanggang jahe gajah segar pada suhu $320^{\circ} \mathrm{C}$ selama $2-10$ menit dan merebus jahe gajah segar pada suhu $100^{\circ} \mathrm{C}$ selama 2-10 menit. Selanjutnya, ekstrak jahe yang telah mengalami proses pemanasan dianalisis untuk kadar gingerol. Hasil penelitian mereka menunjukkan bahwa kandungan gingerol dalam jahe dipanggang pada suhu $320^{\circ} \mathrm{C}$ selama $2-10$ berkisar antara $0,8 \%-1,9 \%$ sedangkan kandungan gingerol dalam jahe direbus pada suhu $100^{\circ} \mathrm{C}$ selama $2-10$ menit berkisar antara $0,78-2 \%$.

\section{KESIMPULAN}

Evaluasi pengaruh parameter proses (jumlah pelarut, $\mathrm{pH}$ dan suhu) pada ekstraksi Jahe menggunakan cohobation agitated extractor telah dilakukan dan disimpulkan bahwa $\mathrm{pH}$ adalah faktor yang paling berpengaruh . Ekstraksi dengan pelarut 8 liter pada $\mathrm{pH} 6$ dan suhu $100^{\circ} \mathrm{C}$ menghasilkan kandungan Gingerol yang lebih tinggi, yaitu $4 \%$. Ekstraksi pada $\mathrm{pH} 4$ menghasilkan kandungan Gingerol yang lebih rendah.

\section{UCAPAN TERIMA KASIH}

Peneliti mengucapkan terima kasih kepada Ketua Program Studi Diploma III Teknik Kimia, Kepala Laboratorium DIII Teknik kimia Universitas Diponegoro dan teman-teman yang telah membantu dalam penelitian ini.

\section{DAFTAR PUSTAKA}

1. Banerjee, A., Dean Karlan, Jonathan Z., 2015. Enam Evaluasi Acak Kredit Mikro: Pendahuluan dan Langkah Selanjutnya. Volume 7, hal. 1-21

2. Aruoma, OI, Spencer, JPE, Warren, D, Jenner, P, Butler, J dan Halliwell, B (1997) Karakterisasi antioksidan makanan, diilustrasikan menggunakan persiapan bawang putih dan jahe komersial. Kimia Pangan, 60, 149-156.

3. Ramji, Divya., 2007. Isolasi Gingerol dan Shogaols dari Jahe dan Evaluasi Aktivitas Chemopreventive mereka pada Panggilan Kanker Prostat dan Efek Anti-Inflamasi pada 12-Otetradecanoyl-Phorbol-13-Acetate (TPA) -Induced Inflammation Ear Mouse. New Brunswick, New Jersey

4. Onyenekwe, PC \& Hashimoto, S. (1999). Komposisi minyak atsiri jahe Nigeria kering (Zingiber Officinale). Penelitian dan Teknologi Makanan Europcan., 209, 407-410.

5. Williams, CA, Lamprecht, ED, 2008. Beberapa tumbuhan biasa memberi makan dan makanan fungsional lainnya dalam kuda nutrisi: ulasan. The Veterinary Journal Volume 178, hlm. 21-31.

6. Vernin, G dan Parkanya, C (2004) Kimia jahe. Dalam Babu, K. (ed.), Jahe: Genus Zingiber. CRC Press, Boca Raton, FL, USA, hlm. 87-180.

7. Agarwal, Walia S., Dhingra S., Khambay BP, 2001. Penghambatan pertumbuhan serangga, aktivitas antifeedant dan antijamur senyawa yang diisolasi / berasal dari rimpang Zingiber officinale Roscoe (jahe), Forum Teknik: 115129.

8. Hu, J., Guo, Z., Glasius, M. Kristensen, K., Xiao, L., Xu, X., 2011. Ekstraksi Cairan Jahe yang Bertekanan (Zingiber officinale Roscoe) dengan Bioetanol: Suatu Pendekatan yang Efisien dan Berkelanjutan. Jurnal Kromatografi A, Volume 1218 (34), hlm. 5765 - 5773

9. Guenther, E., 1952. The Essential Oils Volume VI. D. Van Nostrand Company Inc., New York

10. Balladin, D, Headley, O, Chang-Yen, I dan McGaw, D (1997) Ekstraksi dan evaluasi prinsip-prinsip pedas utama dari jahe India Barat yang dikeringkan dengan tenaga surya (Zingiber officinale ROSCOE ) rimpang. Energi terbarukan, 12, 125-130.

11. Geankoplis, Christie J. 1993. Proses Transportasi dan Unit Operasi edisi ke-3. Prentice-Hall: New Jersey.

12. Treybal, Robert E.1981.Operasi Transfer 
Massal, edisi ke-3, Mc Graw Hill, Inc, New York.

13. Balladin, DA, Headley, O, Chang-Yen, I dan McGaw, DR (1998) Analisis kromatografi cair tekanan tinggi dari prinsip-prinsip pedas utama jahe India Barat yang dikeringkan dengan tenaga surya (Zingiber officinale Roscoe). Energi Terbarukan, 13, 531-536.

14. Handayani, Dwi., Amalia, Rizka., Endy Yulianto. M., Hartati, Indah., Murni. 2018. Penentuan Faktor-Faktor Yang Berpengaruh selama Ekstraksi Enzimatik Minyak Jahe Menggunakan Enzim Sapi Rumen Terisolasi yang Tidak Bergerak. International Journal of Technology (2018) 3: 455-463.
15. Sarip MS, Morad NA, Ali NAM, Yusof YAM, Yunus MAC, 2014. Kinetika ekstraksi senyawa bioaktif jahe obat menggunakan air tekan panas. Teknologi Pemisahan dan Pemurnian.

16. Purnomo H., Jaya, F. dan Widjanarko SB, 2010. Pengaruh jenis dan waktu pemrosesan termal pada jahe (Zingiber officinale Roscoe) senyawa antioksidan rimpang dan kualitasnya. Jurnal Penelitian Pangan Internasional 17: 335-347.

17. Yulianto ME, Kusumo P., Hartati I.,Wahyuningsih. 2017. Ekstraksi Air Subkritis Gingerol dari Zingiber Officinale. Jurnal Kimia Rasayan. Vol. 10. No. 1 